\title{
Medindo a satisfação dos estudantes em relação ao curso introdutório de cuidados em feridas ofertado pela liga de feridas e curativos - LAFEC
}

\author{
Measuring student satisfaction with the introductory wound care course offered by the league of \\ wounds and dressings - LAFEC
}

\author{
Hugo Santana dos Santos Junior ${ }^{1 *} \bullet$, Nayane Beatriz Brito Sales ${ }^{2} \bullet$, Wenny de Souza Alencar ${ }^{3} \bullet$, \\ Karla Katariny Nitão Loureiro Benedito Gomes ${ }^{\bullet}$, Cilene Aparecida de Souza Melo ${ }^{\natural}$, Percilia \\ Augusta Santana da Silva ${ }^{60}$
}

\begin{abstract}
${ }^{1}$ Graduando no Curso de Enfermagem da Faculdade de Teologia, Filosofia e Ciências Humanas - Gamaliel, Tucuruí, Pará, Brasil. ${ }^{2}$ Graduanda no Curso de Enfermagem da Faculdade Carajás, Marabá, Pará, Brasil. ${ }^{3}$ Graduanda no Curso de Enfermagem da Faculdade Carajás, Marabá, Pará, Brasil. ${ }^{4}$ Enfermeira Docente na Faculdade Carajás, Mestranda pelo programa Cirurgia e Pesquisa Experimental UEPA, Marabá, Pará, Brasil. ${ }^{5}$ Enfermeira Mestre em Cirurgia e Pesquisa Experimental, Docente na Faculdade Carajás e Universidade Estadual do Pará - UEPA, Marabá, Pará, Brasil. ${ }^{6}$ Enfermeira Mestre em Cirurgia e Pesquisa Experimental, Docente na Faculdade Carajás e Universidade Estadual do Pará - UEPA, Marabá, Pará, Brasil. *Autor para correspondência. E-mail: hugojuniorbs@bol.com.br
\end{abstract}

\begin{abstract}
Resumo: O objetivo deste estudo é analisar o nível de qualidade e satisfação dos participantes de um curso disponibilizado pela Liga Acadêmica de Feridas e Curativos no município de Marabá estado do Pará, tendo como tema: prevenção e tratamento de feridas realizado no dia 18 de abril de 2019 na Faculdade dos Carajás. Trata-se de um estudo quali-quantitativo, descritivo, analítico, utilizando escalas de mensuração de qualidade tipo Likert, com estruturação de cinco escores de opção, sendo "1" menor satisfação, "3" para imparcialidade demonstrando sem opinião sobre o assunto perguntado e " 5 ” para o maior índice de satisfação, utilizando um grau de confiabilidade $95 \%$ de aceitação para a amostra coletada. Para a construção do questionário, foi identificado as questões de relevância e pertinência dos assuntos para compreender os aspectos de qualidade e satisfação de modo geral dos participantes, dados como sexo, idade, instituição de ensino, formação acadêmica e ocupação profissional auxiliaram na compreensão do público estudado. Amostra obtida somam 42 respostas, de 142 participantes, representando cerca de $29,58 \%$ do total de participantes. Os resultados coletados demonstram mensuração satisfatória para avaliação da qualidade e satisfação de aspectos individuais e gerais do curso, cumprindo os requisitos mínimos de mensuração da qualidade e satisfação através das escalas utilizadas, chegando ao nível de confiança de 95\% de toda a amostra analisada.
\end{abstract}

Palavras-chave: educação em saúde, controle de qualidade, ligas acadêmicas, satisfação pessoal, academias e institutos.

\begin{abstract}
The aim of this study is to analyze the level of quality and satisfaction of participants in a course offered by the Academic League of Wounds and Dressings in the municipality of Marabá, state of Pará, with the theme: prevention and treatment of wounds carried out on April 18, 2019 at the Faculty of Carajás. This is a qualitative-quantitative, descriptive, analytical study, using Likert-type quality measurement scales, with the structuring of five option scores, with " 1 " being less satisfied, " 3 " for impartiality showing no opinion on the question asked and " 5 " for the highest satisfaction index, using a 95\% confidence level of acceptance for the collected sample. For the construction of the questionnaire, issues of relevance and relevance of the subjects were identified to understand the aspects of quality and satisfaction in general of the participants, data such as sex, age, educational institution, academic training and professional occupation helped in the understanding of the public studied. Sample obtained totaled 42 responses, from 142 participants, representing about $29.58 \%$ of the total participants. The collected results demonstrate satisfactory measurement for evaluating the quality and satisfaction of individual and general aspects of the course, fulfilling the minimum requirements for measuring quality and satisfaction using the scales used, reaching the $95 \%$ confidence level of the entire sample analyzed.
\end{abstract}

Keywords: health education, quality control, academic leagues, personal satisfaction, academies and institutes.

\section{Introdução}

O período da Ditadura Militar permitiu um movimento crescente de criação de ligas acadêmicas, o qual surge o debate do ensino universitário e aplicabilidade dos avanços científicos. Portanto, as ligas acadêmicas ganham 
maior atuação através da Constituição de 1988, quando houve o princípio da indissociabilidade entre ensino, pesquisa e extensão e obtendo maior atuação nas universidades (Silva et al., 2015; Silva \& Flores, 2015).

Nesta perpectiva, as ligas acadêmicas são estruturadas por grupos de discentes e docentes de qualquer curso de ensino superior, vinculados a instiruições de ensino, que buscam o conhecimento científico através de atividades de extensão, pesquisa e ensiso, buscando o aprimoramento acadêmico e profissional (Baptista et al., 2014).

Para Hamamoto Filho (2011) as Ligas Acadêmicas são “[...] formadas por estudantes de cursos da área da saúde, coordenadas por profissionais associados à instituição ou ao hospital de ensino e regidas por estatuto próprio. Ofertam basicamente estruturas que contemplam o tripé ensino, pesquisa e extensão, através de seminários, aulas, discussões, apresentações de casos clínicos, atividades práticas, contato com pacientes, estágios, publicações de artigos, entre outros. As ligas são mantidas por um sistema financeiro autossustentável, no qual são fornecidos cursos e workshops, e são arrecadados fundos provenientes de patrocínios de empresas e bolsas universitárias. São entidades que vem conquistando progressivamente espaço no ambiente universitário em virtude do seu potencial de contribuição no ensino".

Em seus trabalhos, alguns autores descrevem que a formação academica de forma qualificada de um profissional da saúde, segue vários princípios que servem de base para a fundamentação do olhar científico. Para que isso seja alcançado deve-se comtemplar vários aspectos, dentre eles, o sistema de saúde, a equipe multiprofissional e a atenção integral à saúde perpetuam essa base (Recine, 2018).

Seguindo este pensamento, o Brasil desenvolveu em suas diretrizes básicas da educação que as universidades brasileiras devem ter "[...] prerrogativa de criação, expansão, modificação e extinção de cursos e programas de educação superior; fixação dos currículos de seus cursos e programas; planificação e programação de pesquisa científica e de atividades de extensão, além da elaboração da programação dos cursos" (Brasil, 1996).

O desenvolvimento das ligas em instituições acadêmicas se torna efetiva no processo ensino aprendizagem com o objetivo dos discentes se aprofundarem em áreas de conhecimentos específicos (Cavalcante et al., 2018).

Com isso, a Liga Acadêmica de Feridas e Curativos (LAFEC) é uma iniciativa da Faculdade Carajás de Marabá associado ao Curso de Enfermagem desta mesma instituição, composto a princípio por graduandos de enfermagem, e com a missão de estimular o estudo das feridas e curativos, visando a melhor formação dos alunos e à qualidade no atendimento.

Inicialmente a LAFEC possui 36 participantes, 6 diretores votados em assembleia e 2 professoras orientadoras. A LAFEC possui calendário próprio a qual promove aulas teórico-práticas ministradas quinzenalmente por membros ligantes e da diretoria; incentiva trabalhos e pesquisas científicas; e realiza eventos voltados para a população.

O objetivo do presente estudo foi avaliar a satisfação dos participantes do Curso Introdutório da LAFEC, cujo o tema é a Prevenção e Tratamento de Feridas, onde foi abordado os seguintes tópicos: Aspectos Gerais da Pele; Classificação e Avaliação das Feridas; e Tratamento de Feridas. Especificamente, pretendeu-se verificar quantitativamente e qualitativamente a efetividade do conteúdo desenvolvido pela LAFEC.

\section{Materiais e métodos}

Abordagem quali-quantitativa, descritiva, analítica, de uma população de 142 participantes do I Curso Introdutório da Liga Acadêmica de Feridas e Curativos (LAFEC). Foram estabelecidos como critérios de inclusão ter participado do I curso Introdutório da LAFEC e aceitar participar do estudo. O Curso Introdutório da Liga, cujo qual abordou a temática: prevenção e tratamento de feridas, com carga horária de 4 horas em que foram ministradas três palestras com os respectivos temas: Aspectos gerais da pele, ministrada pela Enfermeira Cilene Aparecida de Souza, mestre em cirurgia e pesquisa experimental- UEPA, classificação e avaliação de feridas, decorrida pelo enfermeiro Fabrício Eleres, mestrando em tecnologia e inovação em enfermagem- UNIFOR, e tratamento de feridas, apresentada pela enfermeira Luanda da Silva Brasil, membro efetivo da comissão de prevenção e tratamento de feridas do Hospital regional Dr. Geraldo Veloso, no município de Marabá.

O evento ocorreu no auditório da Faculdade dos Carajás. Ao final do curso, após 3 dias, os participantes foram convidados a participar do estudo, tendo sido informado dos seus objetivos e do caráter anônimo e voluntario de sua participação. A avaliação de satisfação foi realizada através da aplicação de um questionário online, criado pela plataforma Google Formulários, disponibilizado de forma gratuita, que teve como objetivo analisar e descrever a população quanto a instituição de ensino, formação acadêmica dos profissionais, ocupação laboral, idade e sexo. 
O questionário foi cosntuído tendo como base o modelo proposto por Júnior \& Costa (2014), que propõem que os dados estruturais do questionário, deve possuir afirmações, positivas, neutras ou negativas em relação a vários aspectos sobre as quais o participante expressa a sua opinião em relação o nível de satisfação a respeito: do tema geral apresentado, dos temas específicos e sua ordem de exibição, didática dos palestrantes, da adequação dos temas apresentados de acordo com o público participante, o dinamismo, participação e interação do palestrante com o público, da oportunidade de aprender reciclar e aprimorar conhecimentos sobre os assuntos abordados no curso, do tempo de cada palestra, da forma de divulgação, preço cobrado e organização da equipe organizadora, da estrutura oferecida e o ambiente onde o curso foi realizado.

Questionário embasado utilizando a técnica da escala Likert, onde se utiliza variação de cinco pontos, em que "1" a primeira escolha representa o menor nível de satisfação e " 5 " representando o maior valor de satisfação, o aspecto de imparcialidade é garantido através da opção de resposta "sem opinião", onde o indivíduo se não possuir satisfação ou insatisfação acerca do tema questionado, poderá responder. A escala também descreve que para a mensuração do nível de qualidade e satisfação, o perfil de aceitação deve cumprir um requisito de no mínimo 95\% em relação ao total da amostra coletada e analisada (Dalmoro \& Vieira, 2013).

Após a coleta de dados através do questionário criado através Google Formulários, a análise estatística descritiva dos dados foi realizada através do programa Microsoft Office Excel ${ }^{\circledR}$ com produção de gráficos.

\section{Resultados}

Após a aplicação dos questionários chegamos aos resultados demonstrados nos gráficos, que contemplam informações sobre a formação, ocupação profissional, idade e sexo, entre outros apresentados no gráfico a seguir.

\section{Formação acadêmica dos participantes}

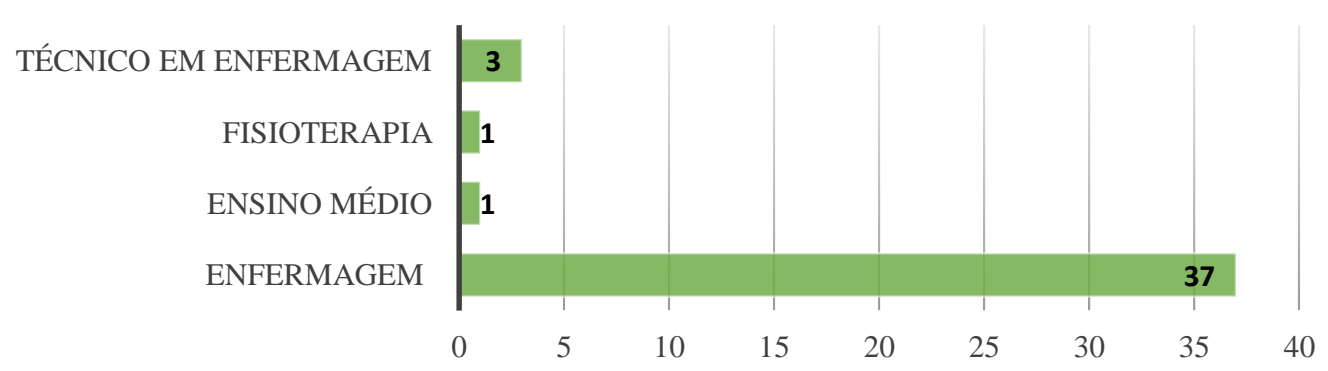

Figura 1. Gráfico do quantitativo de participantes em relação a suas formações acadêmicas. Fonte: dados da pesquisa (Autores, 2019).

Observa-se no gráfico que para os 42 questionários respondidos de forma completa, a formação acadêmica mais representativa em participação foi o curso de bacharelado em enfermagem, totalizando 37 participantes cerca de $88 \%$ do número total de participantes, o curso de fisioterapia representou apenas 1 participante e de formação técnica em enfermagem somam apenas 3 , um participante informou que está na formação em nível médio sem vínculo com curso de formação superior em saúde de acordo com o gráfico 1 .

\section{Ocupação/Profissão}

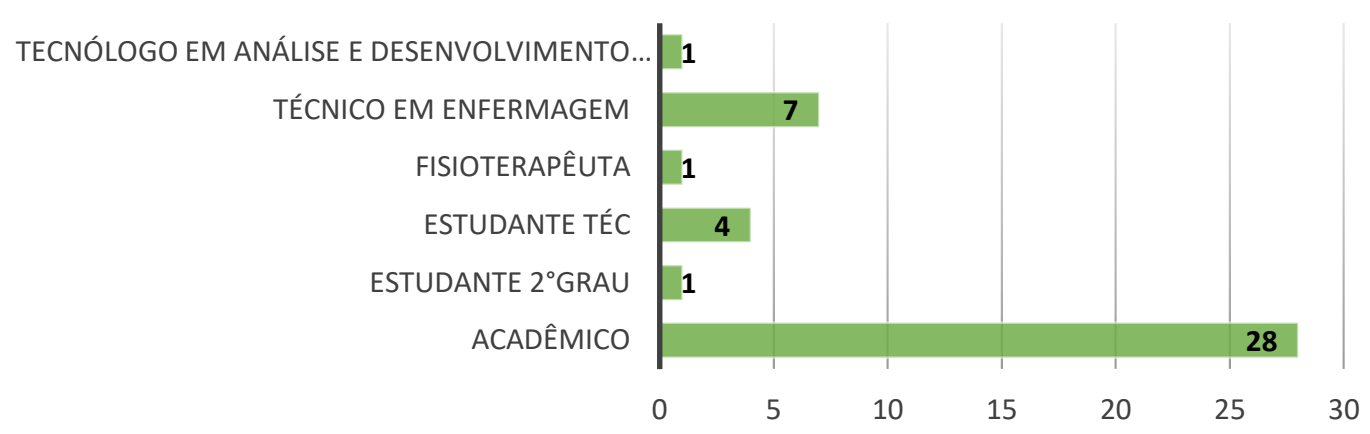

Figura 2. Gráfico do quantitativo de participantes em relação a suas ocupações profissionais. Fonte: dados da pesquisa (Autores, 2019). 
O Gráfico 2 demonstra a ocupação profissional dos participantes do curso disponibilizado pela liga no dia 18 de abril de 2019 na Faculdade dos Carajás, o público acadêmico de nível superior soma 28 participantes no total, representando $66,6 \%$ do número total de participantes, 7 indivíduos relataram que sua ocupação profissional é técnica de enfermagem, 1 fisioterapeuta, 1 participante é tecnólogo em análise e desenvolvimento de sistemas e 4 participantes informaram que ainda estavam cursando a formação técnica em enfermagem, e somete um participante é estudante do nível em ensino médio.

\section{Instituição de Ensino}

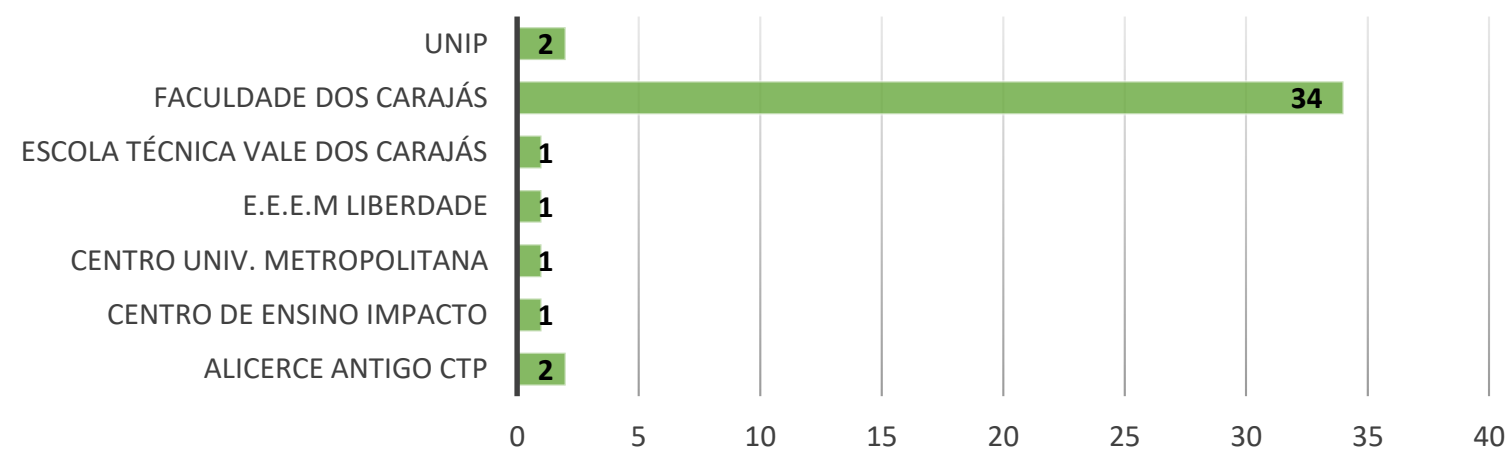

Figura 3. Gráfico do quantitativo de participantes em relação as instituições de ensino superior. Fonte: dados da pesquisa (Autores,2019).

No quesito de vínculo com instituição de ensino superior ou escola de formação técnica, o total de 34 participantes relataram que eram da Faculdade dos Carajás, representando cerca de $81 \%$ do número total, 2 participantes da Universidade Paulista, 1 participante do Centro Universitário Metropolitana de Marabá, 4 participantes de escola de formação técnica, sendo 1 do Centro de Ensino Impacto, 2 da escola técnica Alicerce e 1 da escola técnica Vale dos Carajás como demonstrado no gráfico 3.

\section{Faixa Etária dos Participantes}

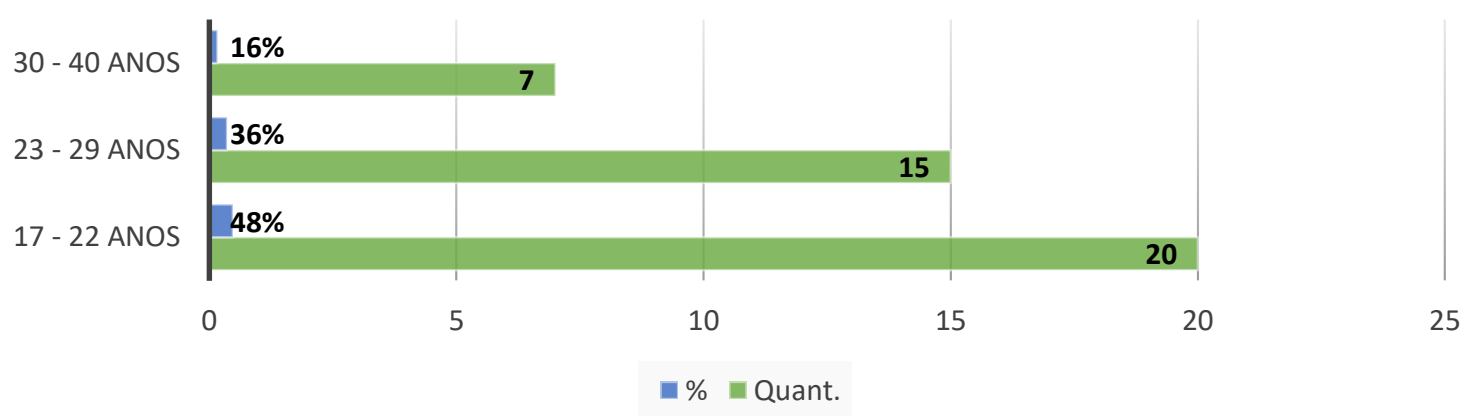

Figura 4. Gráfico do quantitativo de participantes em relação as faixas etárias. Fonte: dados da pesquisa (Autores,2019).

\section{Sexo dos Participantes}

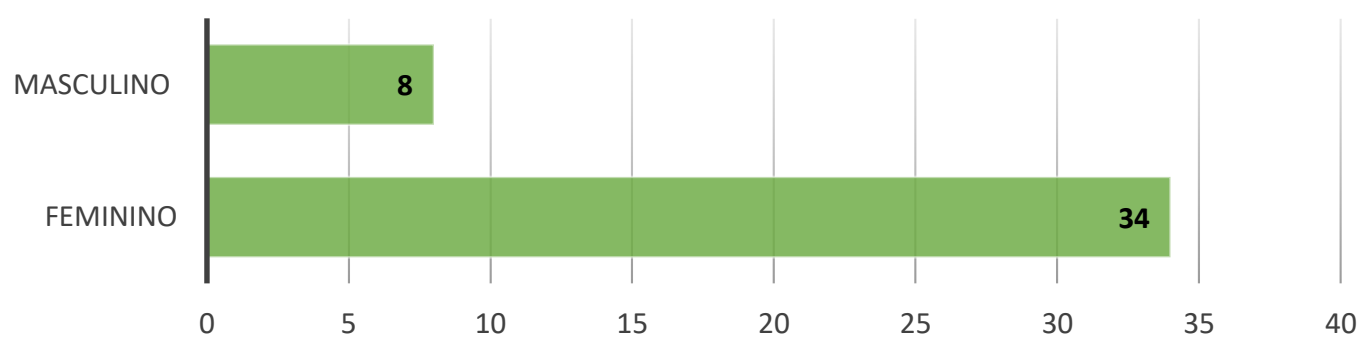

Figura 5. Gráfico do quantitativo de participantes em relação ao sexo. Fonte: dados da pesquisa (Autores,2019). 
Os gráficos 4 e 5 demonstram as faixas etárias dos participantes e o sexo, 20 participantes entre 17 e 22 anos é o público de maior peso, representando $48 \%$ do número total, em seguida 15 participantes entre 23 e 29 anos somando $36 \%$ ao número total e por fim 7 participantes de 30 a 40 anos representando $16 \%$ ao total. Acerca do sexo dos participantes, os dados obtidos foram 34 do sexo feminino e apenas 8 do sexo masculino, $81 \%$ e $19 \%$ respectivamente.

\section{Resumo das Respostas para Avaliação da Qualidade}

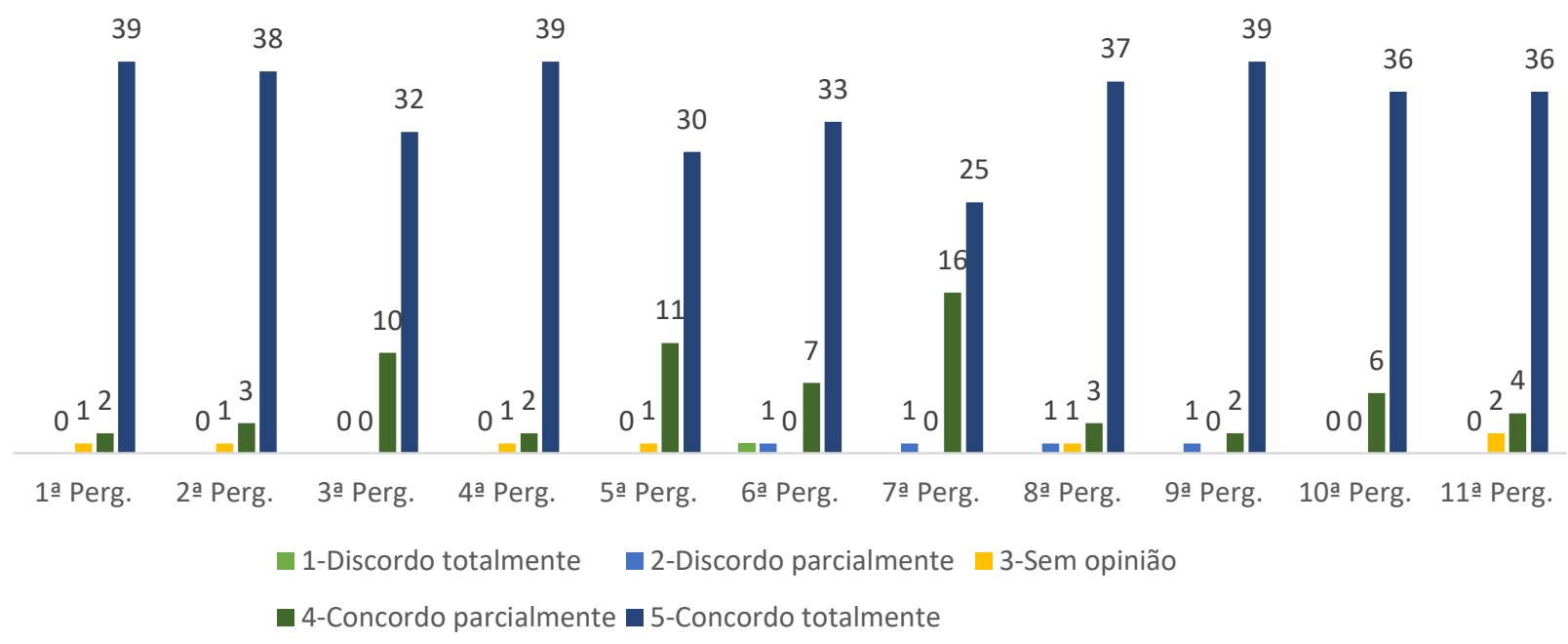

Figura 6. Gráfico do quantitativo das resposta dos participantes sobre a avaliação de qualidade do curso. Fonte: dados da pesquisa (Autores, 2019).

O gráfico 6 representado acima demonstra o quantitativo de respostas para as perguntas de avaliação que compunha o questionário, sendo as opções de resposta discordo totalmente, discordo parcialmente, sem opinião, concordo parcialmente e concordo totalmente.

Para a primeira pergunta, onde foi questionado sobre "Estou de acordo e satisfeito com o tema geral apresentado no curso" obteve-se as seguintes respostas, 39 pessoas responderam que concordam totalmente, 2 que concordam parcialmente e 1 que demonstrou não ter opinião sobre o assunto. As respostas da segunda pergunta, onde foi perguntado "Estou satisfeito e de acordo com os temas específicos e suas ordens de exibição, sendo apresentados em aspectos gerais da pele, classificação e avaliação de feridas e por fim tratamento de feridas" as respostas foram 38 concordo totalmente, 3 participantes responderam que concordavam parcialmente e apenas 1 sem opinião.

A terceira e quarta questão, onde foi perguntado "Estou satisfeito com a didática e qualidade dos palestrantes de modo geral", "Estou satisfeito com adequação dos temas apresentados, sua relevância para minha formação acadêmica" respectivamente, os resultados foram 32 concordam totalmente e 10 concordam parcialmente para a terceira questão, 39 concordam totalmente, 2 concordam parcialmente e apenas 1 sem opinião para a quarta questão. A quinta questão pergunta "Estou satisfeito com o dinamismo, participação e interação dos palestrantes com público" obteve-se 30 concordo totalmente, 11 concordo parcialmente e 1 sem opinião.

Em relação a sexta e sétima questão, onde foi perguntado aos participantes "Estou satisfeito com a oportunidade de aprender, reciclar ou aprimorar meus conhecimentos acerca desse assunto, o curso supriu minhas expectativas" e "Estou satisfeito com o tempo de cada palestra e o tempo de modo geral do curso, sendo de 4 horas no total" respectivamente, os resultados obtidos foram 33 participantes concordaram totalmente, 7 concordam parcialmente, 1 discorda parcialmente e 1 discorda totalmente para sexta pergunta, os resultados da sétima foram 25 concordam totalmente, 16 concordam parcialmente e apenas 1 discorda parcialmente.

Chegando a oitava e nona questão, onde as perguntas seguiram "Estou satisfeito com a forma de divulgação e preço cobrado ao curso, fui bem atendido por toda a equipe organizadora e todo o suporte técnico", "Estou satisfeito com a estrutura oferecida e o ambiente onde o curso foi ministrado, cadeiras, climatização, som e vídeo" os dados foram 37 concordam totalmente, 3 participantes concordam parcialmente, 1 sem opinião e 1 discorda parcialmente quando analisado os dados da oitava questão, a nona demonstra que 39 concordam totalmente, 2 concordam parcialmente e 1 discorda parcialmente. 
Por fim quando analisado os dados da décima e décima primeira questão, onde foi perguntado "Estou de acordo e satisfeito com os aspectos globais do curso, organizacionais, a temática, estrutura física, custo benéfico e divulgação, didática dos palestrantes" e "Estou de acordo que existe grande chance de participar das realizações futuras dessa liga tais como, cursos, palestras, simpósios, ações entre outras" obteve os seguintes dados, 36 concordam totalmente, 6 concordam parcialmente e as demais opções de resposta não apresentam números de escolha para a décima questão, ao observar a décima primeira questão 36 concordam totalmente, 4 concordam parcialmente e 2 sem opinião.

\section{Discussão}

Os dados coletados demonstram grande participação do público acadêmico no geral, especialmente os acadêmicos de bacharelado em enfermagem e técnico em enfermagem, os demais cursos também possuem significativa representação. Acerca do sexo e faixa etária de maior peso em geral, o sexo feminino representa o maior número de participantes, demonstrando ainda maior inclusão do público no curso e na profissão, a faixa etária de maior representatividade é entre 17 a 22 anos, público jovem e recém inserido no meio acadêmico, demonstrando que o jovem cada vez mais tem buscado a aperfeiçoamento científico e tecnológico nas mais diversas áreas da saúde.

Em contra partida a esses resultados, obteve-se importante observância aos aspectos gerais do curso, relevante participação e interação, descrevendo os pontos positivos e negativos, desde os aspectos didáticos e de materiais como os diapositivos, até mesmo o ambiente e suporte técnico oferecido, análises fundamentais e estruturais foram feitas, dicas e sugestões de forma objetiva subjetiva foram coletadas. Percebe-se que o público participante compreendeu o conteúdo proposto para o curso, contudo algumas respostas, principalmente quando analisamos o tempo de duração total do curso e individual das palestras, divulgação, logística entre outros, os aspectos configuram o cenário de respostas demonstram que alguns participantes não representaram sua opinião ou até mesmo discordaram parcialmente sobre.

Após a análise dos resultados obtidos com a aplicação do questionário, observa-se que o público participante foi satisfatório para compor a amostra, contudo o total de 142 participantes do curso introdutório, apenas 42 indivíduos responderam ao questionário enviado, representando cerca de $29,58 \%$ do público total do curso. Apesar de grande parte dos participantes não terem respondido ao questionário, a amostra coletada contribuiu para aferição do nível de satisfação e aspectos de qualidade do curso, cerca de $1 / 5$ do público total de participantes responderam, gerando dados confiáveis e de certo modo contemplando o nível mínimo de respostas para a avaliação do índice de satisfação.

A amostra total demonstra total confiabilidade de modo geral nos seus aspectos metodológicos, estruturais e de coleta de dados, alcançando nível satisfatório em percentagem, utilização de forma correta e concisa da escala de Likert padronizada para criação e estruturação do questionário que implica diretamente na qualidade da amostra coletada (Matos \& Trez, 2012).

\section{Considerações finais}

Entende-se então que através dos dados coletados, trabalhados e analisados, entendendo os padrões de qualidade e satisfação, utilizando de forma coerente e satisfatória a escala de Likert e chegando até os $29,58 \%$, cerca de $1 / 5$ do público total de participantes, o curso introdutório obteve pontuação de qualidade palpável e positiva nos seus aspectos gerais, demonstra nível de satisfação dos participantes, cumprindo o preconizado de $95 \%$ de aceitação satisfatória acerca da amostra coletada.

Pode-se então concluir que o objetivo do trabalho foi de certo modo alcançado, ressaltando que cumpriu os aspectos metodológicos, estruturais, qualitativos e quantitativo para mensuração efetiva e eficaz do nível de satisfação dos participantes de modo geral, contudo técnicas variadas e inclusão de aspectos tecnológicos devem ser considerados nos próximos eventos e estudos acerca dessa temática, engajamento dos participantes acerca do interesse de participação dos estudos devem ser encorajados, busca por aprimoramento nas forças e abordagem dos conteúdos podem ser desenvolvidos, reformulação de aspectos considerados deficitários devem ser analisados e modificados, acarretando assim, com as propostas de melhora em conjunto configurar um cenário de maior qualidade e por sua vez desenvolver a satisfação em amplo aspecto. 


\section{Referências}

Baptista, R. C. N., Martins, J. C. A., Pereira, M. C. R., Mazzo, A. 2014. Satisfação dos estudantes com as experiências clínicas simuladas: validação de escala de avaliação. Revista Latino-Americana de Enfermagem, 22(5), 709-715.

Brasil. 1996. Lei no 9.394, de 20 de dezembro de 1996. Estabelece as diretrizes e bases da educação nacional. Diário Oficial da União, 134(248).

Cavalcante, A. S. P., Vasconcelos, M. I. O., Lira, G. V., Henriques, R. L. M., Albuquerque, I. N. M., Maciel, G. P., ... \& Gomes, D. F. 2018. As ligas acadêmicas na área da saúde: lacunas do conhecimento na produção científica brasileira. Revista Brasileira de Educação Médica, 42(1), 199-206.

Dalmoro, M., \& Vieira, K. M. 2013. Dilemas na construção de escalas Tipo Likert: o número de itens e a disposição influenciam nos resultados?. Revista gestão organizacional, 6(3).

Google Drive, Ferramenta Google Formulários, Ferramenta de construção de formulários. Disponível em: https://drive.google.com/drive/u/2/my-drive. Acesso em: 28 de abr. 2019.

Hamamoto Filho, P. T., Venditti, V. C., Oliveira, C. C., Vicentini, H. C., \& Schellini, S. A. 2011. Ligas Acadêmicas de Medicina: extensão das ciências médicas à sociedade. Revista Ciência em Extensão, 7(1), 126-133.

Júnior, S. D. D. S., \& Costa, F. J. 2014. Mensuração e escalas de verificação: uma análise comparativa das escalas de Likert e Phrase Completion. PMKT-Revista Brasileira de Pesquisas de Marketing, Opinião e Mídia, 15(1-16), 61.

Matos, C. A., \& Trez, G. 2012. A influência da ordem das questões nos resultados de pesquisas surveys. Revista de Administração FACES Journal, 11(1), 151-172.

Recine, E., Alves, K. P. D. S., Monego, E., Sugai, A., \& Melo, A. C. M. 2018. Formação profissional para o SUS: análise de reformas curriculares em cursos de graduação em nutrição. Avaliação: Revista da Avaliação da Educação Superior, 23(3), 679-697.

Silva, J. H. S. D., Chiochetta, L. G., Oliveira, L. F. T. D., \& Sousa, V. D. O. 2015. Implantação de uma liga acadêmica de anatomia: desafios e conquistas. Revista Brasileira de Educação Médica, 39(2), 310-315.

Silva, S. A. D., \& Flores, O. 2015. Ligas Acadêmicas no Processo de Formação dos Estudantes. Revista Brasileira de Educação Médica, 39(3), 410-417.

\section{Minicurrículo}

Hugo Santana dos Santos Junior. Acadêmico do curso de bacharelado em enfermagem, na Faculdade de Teologia, Filosofia e Ciências Humanas - GAMALIEL, Tucuruí-PA. Ex-monitor da Disciplina de Neuroanatomia/Neurociência durante dois semestres, Marabá-PA. Participou da mesa diretora de criação das ligas LISAMU e LAFEC, Liga Interdisciplinar Saúde da Mulher e Liga Acadêmica de Feridas e Curativos, Marabá-PA. Atualmente faz parte do NPI - Núcleo de Apoio Intelectual do programa de Mestrado CIPE, Cirurgia e Pesquisa Experimental da Universidade Estadual do Pará - UEPA.

Nayane Beatriz Brito Sales. Enfermeira graduada pela Faculdade dos Carajás, Marabá-Pará. Tem experiência na área da Saúde, com ênfase em Enfermagem.

Wenny de Souza Alencar. Acadêmica do curso de bacharelado em enfermagem pela Faculdade dos Carajás, Marabá-Pará. Participou da mesa diretora de criação das ligas LISAMU e LAFEC, Liga Interdisciplinar Saúde da Mulher e Liga Acadêmica de Feridas e Curativos, Marabá-PA.

Karla Katariny Nitão Loureiro Benedito Gomes. Mestranda Profissional em Cirurgia Experimental (LCE), UEPA. Graduada em Enfermagem pela Universidade Federal da Paraíba (2006). Pós Graduada em Bloco Cirúrgico pela Universidade Federal da Bahia (2011) e em Saúde da Família com ênfase na implantação das 
linhas de cuidado, pela Universidade Federal da Paraíba (2014). Docente da Graduação de Enfermagem da Faculdade Carajás. Tem experiência nas áreas de Centro cirúrgico, UTI neonatal e adulto, clínica obstétrica,home care, clínica médica e cirúrgica, epidemiologia, área comercial e de gestão.

Cilene Aparecida de Souza Melo. Mestre em Cirurgia e Pesquisa e Experimental - LCE/UEPA (2018). Docente do eixo morfofuncional da graduação em Medicina e Coordenadora do Laboratório de Anatomia da Universidade do Estado do Pará - UEPA - Campus VIII - Marabá - PA. Coordenadora dos laboratórios e docente da graduação em Enfermagem na instituição Faculdade Carajás - Marabá - PA. Possui graduação em Enfermagem pelo Centro Universitário de Lavras (2007), com Especialização em Enfermagem do Trabalho (2012) Enfermagem em Dermatologia (2016), Enfermagem Oncológica (2018) e Anatomia Funcional (2018).

Percilia Augusta Santana da Silva. Enfermeira Mestre em Cirurgia e Pesquisa Experimental pelo Mestrado CIPE pela Universidade do Estado do Pará. Docente do Curso de Medicina da Universidade do Estado do Pará como professora Substituta Disciplinas Gestão Ensino Interação Comunitária 1 ,2, e 4. Docente do Curso de Enfermagem da Faculdade Carajás nas disciplinas Sistema de Informação SIN, Saúde Coletiva e Administração e Gerenciamento Enfermagem e Seminário Integrador Enfermeira Concursada da Prefeitura Municipal de Marabá, como Instrutora da ESF na Unidade de Saúde Pedro Cavalcante Atualmente Intensivista da Unidade de Cuidados Intensivos Pacientes com COVID no Hospital Municipal de Marabá; Especialista Em Terapia Intensiva pela Universidade do Estado do Pará Especialista em Educação Médica pela Universidade do Estado do Pará. Epidemiologia para os Serviços de Saúde pela Universidade do Estado do Pará, Administração e Gerenciamento Enfermagem pela Universidade Federal de São Paulo. Educação para Profissionais de Saúde pela FIOCRUZ Possui proficiência Inglês pela Universidade Federal do Pará.

Como citar: Santos Junior, H.S., Sales, N.B.B., Alencar, W.S., Gomes, K.K.N.L., Melo, C.A.S, \& Silva, P.A.S. 2020. Medindo a satisfação dos estudantes em relação ao curso introdutório de cuidados em feridas ofertado pela liga de feridas e curativos - LAFEC. Pubsaúde, 4, a082. DOI: https://dx.doi.org/10.31533/pubsaude4.a082

Recebido: 30 set. 2020.

Revisado e aceito: 6 out. 2020.

Conflito de interesse: os autores declaram, em relação aos produtos e companhias descritos nesse artigo, não ter interesses associativos, comerciais, de propriedade ou financeiros que representem conflito de interesse.

Licenciamento: Este artigo é publicado na modalidade Acesso Aberto sob a licença Creative Commons Atribuição 4.0 (CC-BY 4.0). 